\title{
Frequency of Health Care Resource Utilization and Direct Medical Costs Associated with Psoriatic Arthritis in a Rheumatic Care Center in Colombia
}

This article was published in the following Dove Press journal:

Psoriasis: Targets and Therapy

\author{
Pedro Santos-Moreno (iD ${ }^{1}$ \\ Fernando Gómez- \\ De la Rosa $\mathbb{D}^{2}$ \\ Devian Parra-Padilla $\mathbb{D}^{2,3}$ \\ Nelson J Alvis-Zakzuk (iD ${ }^{2,4}$ \\ Nelson R Alvis-Zakzuk ${ }^{2}$ \\ María Carrasquilla- \\ Sotomayor $\mathbb{D}^{2}$ \\ Omaira Valencia (iD) \\ Nelson Alvis-Guzmán (D) ${ }^{2,5}$ \\ 'Biomab IPS - Center for Rheumatoid \\ Arthritis, Bogotá, Colombia; \\ ${ }^{2}$ Department of Health Technology \\ Assessment, ALZAK Foundation, \\ Cartagena, Colombia; ${ }^{3}$ Health Economics \\ Research Group, Universidad de \\ Cartagena, Cartagena, Colombia; \\ ${ }^{4}$ Department of Health Sciences, \\ Universidad de la Costa-CUC, \\ Barranquilla, Colombia; ${ }^{5}$ Department of \\ Economic Sciences, Universidad de \\ Cartagena, Cartagena, Colombia
}

Objective: To estimate the frequency of health care resource utilization and direct medical costs associated with Psoriatic Arthritis (PsA) in a rheumatic care center in Colombia.

Methods: A retrospective prevalence-based cost of illness study under the Colombian health care system perspective was conducted. We analyzed the frequency of health care resource utilization and estimated direct medical costs using anonymized medical records of adult patients ( $\geq 18$ years) diagnosed with PsA at a rheumatology care center in Bogotá, Colombia. Patients were required to have at least one medical visit linked to a PsA diagnosis (ICD-10 L40.5) between October 2018 and October 2019 and a previous diagnose by the CASPAR criteria. Data on hospitalization episodes was not available. Direct medical costs were estimated in Colombian pesos (COP) and reported in US dollars (USD) using an exchange rate of 1USD = 3263.4 COP. A multivariate generalized linear model was used for identifying potential cost predictors.

Results: A sample of 83 patients was obtained. Of these, $54.2 \%$ were women and had a mean (SD) age of 58.7 (12) years at baseline. On average, they had 2.2 and 3.8 medical visits to the dermatologist and rheumatologist in the study period. The total direct medical cost was estimated at 410,985 US Dollars. Medical visits, therapies, laboratory and imaging represented $3.2 \%$ of total expenses and medications the remaining 96.8\%. Patients receiving conventional DMARDs (cDMARDs) had an associated mean cost of 1020.1 USD (CI 701.4-1338.8) in a year. Among patients treated with cDMARDs and biological DMARDs (bDMARDs) the mean cost increase to 8113.9 USD (SD 5182.0-95\% CI 6575.1-9652.8).

Conclusion: A patient under biological therapy can increase their annual cost by 7.9 times the cost of a patient in conventional therapy. This provided updated knowledge on the direct medical costs, from the provision of a rheumatic care center service, to support epidemiologic or pharmacovigilance models.

Keywords: psoriatic arthritis, direct medical costs, treatment

\section{Introduction}

Psoriatic arthritis (PsA) is a common inflammatory disease affecting $1-3 \%$ of the population. $^{1,2}$ A great number of patients with PsA have progressive joint damage, reduced life expectancy, and increasing disability, which is related with a substantial reduction in quality of life. ${ }^{3-5}$ Currently, there is no consensus on prevalence data for this disease. Based on CASPAR (The Classification Criteria for Psoriatic Arthritis) criteria, it is estimated that it occurs in up to $30 \%$ of patients with psoriasis $(\mathrm{PsO})$ and that this progress occurs between 5-10 years after the onset of PsO. ${ }^{6-11}$ PsA annual incidence was reported to be $2-3 \%$ in a prospective study of patients with psoriasis. ${ }^{6,12}$
Correspondence: Nelson J Alvis-Zakzuk Department of Health Sciences

Universidad de la Costa-CUC, Calle 58 \#

55 - 66, Barranquilla, Colombia

Tel +573002209164

Email nalvisI@cuc.edu.co
Psoriasis: Targets and Therapy 2021:11 31-39

31

DovePress $\boldsymbol{f}$ in $\boldsymbol{\nabla}$

http://doi.ror/10.2147/PTT.S270621 (c) (1) (\$) $\odot 2021$ Santos-Moreno et al. This work is published and licensed by Dove Medical Press Limited. The full terms of this license are available at https://www.dovepress.com/ the work you hereby accept the Terms. Non-commercial uses of the work are permitted without any further permission from Dove Medical Press limited, provided the work is properly atrributed. For permission for commercial use of this work, please see paragraphs 4.2 and 5 of our Terms (https://www.dovepress.com/terms.php). 
Regarding to mortality, patients with rheumatoid arthritis and $\mathrm{PsO}$ had a greater mortality risk compared to the general population, and patients with PsA did not have a significantly elevated risk of mortality. ${ }^{13}$ The continuous research of the global burden of disease (GBD) does not show mortality data associated with this pathology, however, according to some studies, the causes of mortality in PsA are associated with patient comorbidities. ${ }^{14,15}$

In 2015, The European League Against Rheumatism (EULAR) and the Group for Research and Assessment of Psoriasis and PsA (GRAPPA) published their recommendations for the management of PsA..$^{2,16-18}$ However, these guidelines are principally based on studies performed in high-income settings and may not be applicable in countries in the Americas, as Colombia. Similarly, the prevalence of chronic disease is also increasing in low-and middle-income countries. ${ }^{2,19}$ Then, the management of PsA and associated non-communicable as well as infection-related comorbidities is challenging in countries with economic constraints, and will need to be addressed in future research studies given the lack of literature. ${ }^{2,19}$

Currently, there is no clinical practice guideline from the Ministry of Health in Colombia that documents the optimal treatment of PsA. The therapeutic care protocol for patients with PsA is varied, beginning with conventional therapy due to its almost generalized application that includes topical agents, analgesics, non-steroidal antiinflammatory drugs (NSAIDs), and synthetic/conventional disease-modifying antirheumatic agents (cDMARDs). In the second instance, depending on clinical results, therapeutic adherence, and disease evolution, treatment with biological therapy (bDMARDs) is started. ${ }^{17,20-22}$

Studies describing the frequency of health services utilization and evaluating the costs of musculoskeletal disorders (MSK), apart from rheumatoid arthritis (RA) are limited in low-and middle-income countries. Following these considerations, the aims of the present study were: 1) to characterize a cohort of patients diagnosed with PsA from an outpatient rheumatic care center, and 2) to estimate the healthcare resource utilization associated with their treatment and the direct medical costs of caring for patients with PsA during a year.

\section{Methods}

\section{Study Design}

This was a prevalence-based cost-of-illness study conducted from the perspective of the Colombian health care system.
This system, with a high insurance coverage of the population $(94.6 \%),{ }^{23}$ comprises healthcare attention for poor population (subsidized regime), for people who works (contributive regime), for military, teachers and others (special regime), and for those who have willingness-to-pay for private attention (out-of-pocket or private expenditure). ${ }^{24,25}$

We retrospectively analyzed anonymized medical records of a sample of patients with a previous diagnose of PsA. Patients were included if at least one medical record linked to a PsA L40.5 ICD-10 code was observed and had a previous physician-diagnosed PsA under the CASPAR classificatory criteria. $^{26}$ In addition, patients were required to have at least 18 years of age at baseline, and one year of clinical follow-up to be included in the study. Indirect or intangible costs associated with PsA were not assessed. To ensure the quality of estimations, only health care services and medication utilization associated with PsA were considered. A member of the research staff reviewed the administrative data from the resulting sample to exclude those registries not associated to the management of PsA.

\section{Data Sources}

The primary data source was an administrative database of medical records of patients treated at an outpatient rheumatic care center in Bogotá, Colombia from October 1, 2018 to October 31, 2019. Patient-level data on sociodemographic characteristics (ie, age, sex), comorbidities, and health care resource utilization per-service or medication were available for analysis. No information regarding emergency department visits or hospitalizations was available for the study.

\section{Cost Calculation}

The healthcare resource utilization on medical consultations with general and specialized physicians, physical therapy, laboratory tests and imaging, and other services (infusion therapy and pharmacovigilance) were valued using prices of the rheumatology center. These fees are the result of negotiations between the center and the insurer of the studied patients. At the same time, activities prescribed and related to the disease that were not provided by the rheumatology care center were valued using national tariffs, as is recommended by the Methodological Manual for the Elaboration of Economic Evaluations in Health of the Institute of Technological Evaluation in Health (IETS, in Spanish). ${ }^{27}$ Individual costs inputs of medications were obtained from the consolidated database of market trends of pharmaceutical sales from the Drug Price Information System in Colombia (Sistema de Infrormación de Precios de Medicamentos - 
SISMED) between October, 2018 and October, 2019. ${ }^{28}$ SISMED is the official source of drug prices in Colombia and provides detailed information regarding the frequency of units sold, minimum, and maximum prices of each medication currently commercialized in the country. Cost inputs of medical services were retrieved from Instituto de Seguros Sociales price list, adding $30 \%$, as is recommended by the IETS. $^{27,29}$ The IETS is Colombia's economic evaluation agency and its mission is to produce evidence-based information to contribute to the development of better public policies and healthcare practices (Law 1438 of 2011). ${ }^{30}$

For reporting, costs were shown by sex, age groups $(<60$, $\geq 60$ years), type of therapy (biological or conventional), and cost items. All costs were reported in US dollars using the average market exchange rate reported by the Central Bank of Colombia of 1US $\$$ dollar $=3263.4$ Colombian pesos (COP), between October, 2018 and October, 2019. ${ }^{31}$

\section{Statistical Analysis}

Continuous variables were expressed as means, medians, and standard deviation (SD), while categorical variables were reported with relative frequencies and absolute frequencies. To establish the differences in the distribution of continuous variables (costs) for categorical variables (sex), the MannWhitney test was used because the cost variable was not normally distributed. ${ }^{32}$ A generalized multivariate linear regression model assuming a log-link and gamma distribution was used to identify potential cost predictors. ${ }^{33,34}$ The coefficients estimated trough the multivariate model were expressed in their exponentiated form to indicate cost ratios between categories of predictors. A p-value $<0.050$ was considered statistically significant. The data was organized in Microsoft ${ }^{\circledR}$ Excel and analyzed in Python (v.3.7).

\section{Ethical Considerations}

This study was approved by the Biomab IPS Research Committee in February 2019. All patients had previously signed informed consent for data use. This study did not represent risks for the patients; all data that could identify a patient were anonymized. This study was classified as risk-free, according to Resolution 8430 of 1993 of the Colombian Ministry of Health. ${ }^{35}$

\section{Results}

\section{Sample Characteristics}

Table 1 shows the sociodemographic characteristics of the patients. Eighty-three patients were analyzed, $54.2 \%$ were
Table I Baseline Sociodemographic Characteristics of the Study Sample

\begin{tabular}{|l|r|}
\hline Characteristics & n (\%) \\
\hline N & 83 \\
\hline Sex & $45(54.2)$ \\
Female & $58.7(12)$ \\
\hline Age (years) mean (SD) & \\
\hline Comorbidities & $4(4.8)$ \\
Primary hypertension & $3(3.6)$ \\
Intervertebral disc disorders & $3(3.6)$ \\
Obesity & $3(3.6)$ \\
Osteoporosis without fracture & $3(3.6)$ \\
Fibromyalgia & \\
\hline
\end{tabular}

women. The age range for the patients treated in the care center was 25-83 years, with an average of 60.5 years for women and 57.4 years for men. $19.2 \%$ of the patients had any type of comorbidity as hypertension $4.8 \%$, other musculoskeletal disorder $7.2 \%$, obesity $3.6 \%$, and fibromyalgia $3.6 \%$.

\section{Healthcare Resource Utilization}

The annual sum of rheumatology and dermatology consultations for the 83 patients were 317 and 183, respectively. An average of 2 imaging tests was requested per patient, for the 36 who consumed this service. One out of every two patients received consultations by physiatry and of the 30 patients who received physical therapy, the average number of consultations in the year was 2 (Table 2).

Among the analyzed patients, there were three patients (3.6\%) who did not report medication usage. It was found that within the 80 patients, none had exclusive consumption of NSAIDs, 15 patients (18.0\%) consumed a single type of medication, 37 patients $(44.5 \%)$ recorded a mixed consumption of two types, while the mixed consumption of three and four drugs belonged to 28 patients (33.7\%). Among the medications, the formulation of conventional DMARDs prevails, with 71 patients $(81.5 \%)$ demanding it as treatment therapy (Table 3).

\section{Direct Medical Costs of PsA}

The average annual costs according to the demand for health services and medications are shown in Table 4. The economic burden from the third payer perspective associated with the outpatient treatment of the 83 patients was USD 410,985. Medical visits, therapies, laboratory and imaging accounted for USD 13,290.3 (3.2\%), and medications and/or 
Table 2 Frequency of Health Care Services and Medication Utilization

\begin{tabular}{|l|l|l|l|}
\hline Medical Services/Medications & $\mathbf{n}(\%)$ & Mean & SD \\
\hline Medical appointments & & & \\
$\quad$ Rheumatology & $82(98.8)$ & 3.9 & 1.5 \\
Dermatology & $65(78.3)$ & 2.8 & 1.2 \\
Physiatry & $44(53.0)$ & 1.7 & 1.0 \\
Orthopedics & $7(8.4)$ & 1.4 & 0.9 \\
Other specialties* & $30(36.1)$ & 1.8 & 1.2 \\
Physical therapy & $30(36.1)$ & 1.9 & 1.0 \\
\hline Laboratory tests and imaging & $36(43.4)$ & 2.0 & 1.5 \\
\hline Medications & & & \\
NSAIDs+ & $16(19.3)$ & 0.4 & 1.0 \\
Analgesics & $43(51.8)$ & 1.6 & 1.8 \\
Conventional DMARDs** & $71(85.5)$ & 3.6 & 2.8 \\
Biological DMARDs & $46(55.4)$ & 2.2 & 2.2 \\
\hline
\end{tabular}

Notes: *Psychology, infectology, pain and palliative care, nutrition and dietetics, psychiatry.

Abbreviations: +NSAIDs, non-steroidal anti-inflammatory medicine; **DMARDs, disease-modifying antirheumatic drugs.

Table 3 Distribution of Patients According to the Type of Pharmacological Therapy Received

\begin{tabular}{|l|c|l|c|}
\hline $\begin{array}{l}\text { Treatment } \\
\text { without } \\
\text { Biological } \\
\text { Therapies }\end{array}$ & $\begin{array}{c}\text { Number } \\
\text { of } \\
\text { Patients }\end{array}$ & $\begin{array}{l}\text { Treatment Including } \\
\text { Biological Therapies }\end{array}$ & $\begin{array}{c}\text { Number } \\
\text { of } \\
\text { Patients }\end{array}$ \\
\hline NSAIDs & 0 & bDMARDs & 3 \\
\hline Analgesics & 2 & bDMARDs + NSAIDs & 3 \\
\hline cDMARDs & 10 & bDMARDs + cDMARDs & 18 \\
\hline $\begin{array}{l}\text { cDMARDs }+ \\
\text { NSAIDs }\end{array}$ & 0 & $\begin{array}{l}\text { bDMARDs + cDMARDs } \\
+ \text { NSAIDs }\end{array}$ & 3 \\
\hline $\begin{array}{l}\text { cDMARDs }+ \\
\text { analgesics }\end{array}$ & 16 & $\begin{array}{l}\text { bDMARDs + cDMARDs } \\
+ \text { analgesics }\end{array}$ & 15 \\
\hline $\begin{array}{l}\text { cDMARDs }+ \\
\text { NSAIDs }+ \\
\text { analgesics }\end{array}$ & 6 & $\begin{array}{l}\text { bDMARDs + NSAIDs + } \\
\text { analgesics }\end{array}$ & 1 \\
\hline & & $\begin{array}{l}\text { bDMARDs + NSAIDs + } \\
\text { analgesics + cDMARDs }\end{array}$ & 3 \\
\hline
\end{tabular}

Abbreviations: +NSAIDs, non-steroidal anti-inflammatory medicine; cDMARDs, conventional disease-modifying antirheumatic drugs; bDMARDs, biological diseasemodifying antirheumatic drugs.

their application for USD 397,694.3 (96.8\%). The average annual direct medical cost of a male patient was USD 5646.0 (95\% CI 3790.7-7501.3), while the female sex was on average USD 4365.3 (95\% CI 2890.3-5840.3) (Figure 1A).
Table 4 Unadjusted Annual Mean and Median PsA-Related Medical Costs

\begin{tabular}{|l|r|r|r|}
\hline Cost Component & Mean & SD & Median \\
\hline Medical appointments & & & \\
$\quad$ Rheumatology & 54.5 & 21.8 & 56.4 \\
Dermatology & 24.4 & 10.2 & 26.0 \\
Physiatry & 14.8 & 9.1 & 8.7 \\
Orthopedics & 12.2 & 7.8 & 8.7 \\
Other specialties* & 6.3 & 3.6 & 5.7 \\
Physical therapy & 5.9 & 3.2 & 6.1 \\
\hline Laboratory tests and imaging & 51.2 & 52.1 & 21.3 \\
\hline Medications & & & \\
NSAIDs+ & 5.8 & 23.4 & 0.0 \\
Analgesics & 1.9 & 55.6 & 1.7 \\
Conventional DMARDs** & 840.3 & 980.8 & 324.3 \\
Biologic DMARDs & $4,106.1$ & $5,017.0$ & $2,145.0$ \\
\hline
\end{tabular}

Notes: *Psychology, infectology, esp. in pain and palliative care, nutrition, and dietetics, psychiatry.

Abbreviations: +NSAIDs, non-steroidal anti-inflammatory medicine; **DMARDs, disease-modifying antirheumatic drugs.

When comparing patients by age range, an average annual cost of USD 5618.2 (95\% CI 4026.6-7209.7) was found for 48 patients under 60 years of age and an average annual cost of USD 4037.5 (CI 95\% 2360.2-5714.8) for 35 patients aged 60 years or older (Figure 1B).

The average direct medical cost of a patient with PsA receiving therapy with cDMARDs was USD 1020.1 (95\% CI $701.4-1338.8$ ) in the year, while the one receiving some medication together with bDMARDs, the average annual cost amounts to USD 8113.9 (95\% CI 6575.19652.8) (Figure 1C). The annual direct medical cost in men with PsA with conventional therapy was on average USD 607.6 (SD 792.3) and with bDMARDs it was USD 7991.8 (SD 5363.7). In women, these costs were USD 1341.8 (SD 944.6) and USD 8272.6 (SD 5069.4), respectively.

The annual cost for patients by therapy, sex, and age range is reported in Table 5. No statistically significant differences were found in the behavior of total costs by sex (Mann-Whitney: $\mathrm{U}=735, \mathrm{P}=0.13$ ) (Figure 2A). However, a statistically significant cost difference was found between the age ranges for patients under 60 years of age and those 60 years of age or older (Mann-Whitney: $\mathrm{U}=649, \mathrm{P}=0.03$ ) Figure 2B. Among the men, the eight highest values are from the age group of under 60 years with a range of USD 8398.2 - USD19,957. In other words, the sample of those under 60 is made up of 24 men, of whom 20 have biological treatment. 
A Average cost by sex

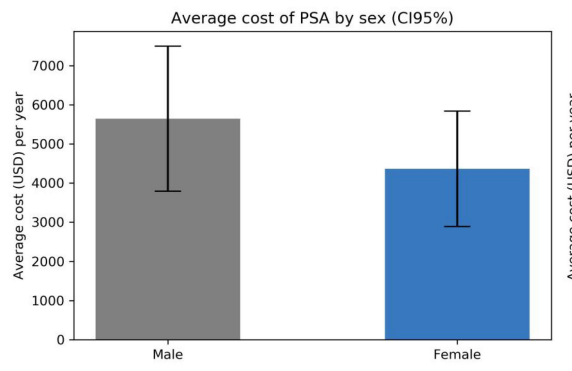

B Average cost by age range

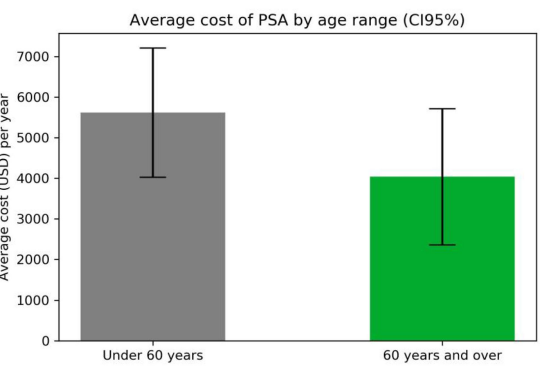

C Average cost by type of DMARD

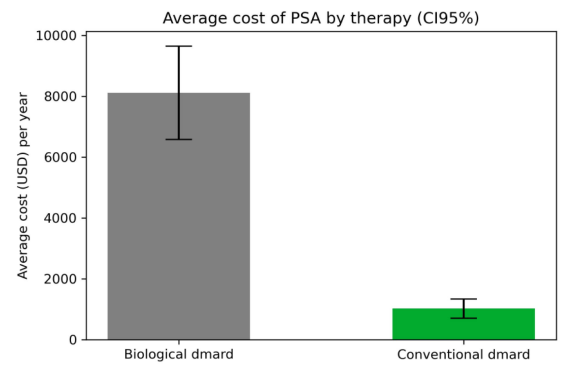

Figure I Comparison of the annual average medical direct cost of PsA by sex, age groups and type of DMARD. (A) Average cost by sex. (B) Average cost by age range. (C) Average cost by type of DMARD.

Notes: $($ A) Ratio male:female $=$ 1.3. (B) Ratio $<60$ years old:60 years and over $=$ I.4. $($ C) Ratio bDMARDs:cDMARDs $=7.9$.

\section{Direct Costs Predictors}

Being a male and having a prescription of a bDMARD were statistically significant predictor variables of higher direct medical costs. No association between costs and having $\geq 60$ years of age was found $(\mathrm{p}=0.110)$. The estimated cost ratios are shown in Table 6 .

\section{Discussion}

According to our knowledge, this one of the first studies to describe the frequency of health services resource utilization and the costs associated with the treatment of patients with PsA in Colombia, and Latin America and the Caribbean (LAC). ${ }^{36}$ Previous analysis have estimated the economic impact of moderate to severe plaque psoriasis in Brazil, but studies on PsA direct medical cost in LAC are not frequent. ${ }^{37}$

The main finding of this study was that the annual direct medical cost of treating a patient with PsA on an outpatient basis was USD 1020 (SD USD 956) with conventional therapy and USD 8114 (SD USD 5182) with biological therapy. These costs are lower than those reported in studies carried out in other countries such as the United States, where in 2014 annual medical direct costs were USD 9860 (2019 costs: USD 10,648.2, adjusted by inflation) excluding hospitalization. ${ }^{38}$ However, our costs were similar to those reported in the systematic review by Burgos-Pol al in five countries in Europe, where the annual direct costs

Table 5 Comparison of Direct Medical Costs According to the Type of Disease Modifying Anti-Rheumatic Drugs Received, Sex and Age Group

\begin{tabular}{|c|c|c|c|c|c|}
\hline \multirow[t]{2}{*}{ Calculations } & \multirow{2}{*}{$\begin{array}{c}\text { Type of Pharmacological } \\
\text { Therapy }\end{array}$} & \multicolumn{2}{|c|}{ Female $(n=45)$} & \multicolumn{2}{|c|}{ Male $(n=38)$} \\
\hline & & $\begin{array}{l}\text { Under } 60 \text { Years } \\
\qquad(n=24)\end{array}$ & $\begin{array}{l}60 \text { Years and Over } \\
(n=21)\end{array}$ & $\begin{array}{l}\text { Under } 60 \text { Years } \\
\qquad(n=24)\end{array}$ & $\begin{array}{c}60 \text { Years and Over } \\
(n=14)\end{array}$ \\
\hline \multirow[t]{2}{*}{ Sum } & cDMARDs & $17.605,0$ & $13.257,0$ & $4.010,2$ & $2.673,9$ \\
\hline & bDMARDs & $75.084,5$ & $90.368,4$ & $172.972,6$ & $34.815,2$ \\
\hline \multirow[t]{2}{*}{ Mean } & cDMARDs & I.354, 2 & $1.325,7$ & $1.002,5$ & 382,0 \\
\hline & bDMARDs & $6.825,9$ & $10.040,9$ & $8.648,6$ & $5.802,5$ \\
\hline \multirow[t]{2}{*}{ Median } & cDMARDs & $1.511,9$ & $1.704,0$ & 489,8 & 325,6 \\
\hline & bDMARDs & $6.466,1$ & $8.369,9$ & $6.435,1$ & $6.205,6$ \\
\hline \multirow[t]{2}{*}{ Min. } & cDMARDs & 88,5 & 162,9 & 111,2 & 140, 2 \\
\hline & bDMARDs & $1.754,2$ & $3.824,6$ & $1.869,7$ & $2.938,9$ \\
\hline \multirow[t]{2}{*}{ Max. } & cDMARDs & $2.903,8$ & $2.747,5$ & $2.919,3$ & 736,0 \\
\hline & bDMARDs & 14.267, 2 & $21.256,4$ & $19.957,0$ & $7.736,4$ \\
\hline \multirow[t]{2}{*}{ SD } & cDMARDs & 956,8 & 979,7 & $1.291,6$ & 221,1 \\
\hline & bDMARDs & $4.555,4$ & $5.357,1$ & $5.926,0$ & I.709, 4 \\
\hline
\end{tabular}

Abbreviations: cDMARDs, conventional disease-modifying antirheumatic drugs; bDMARDs, biological disease-modifying antirheumatic drugs. 

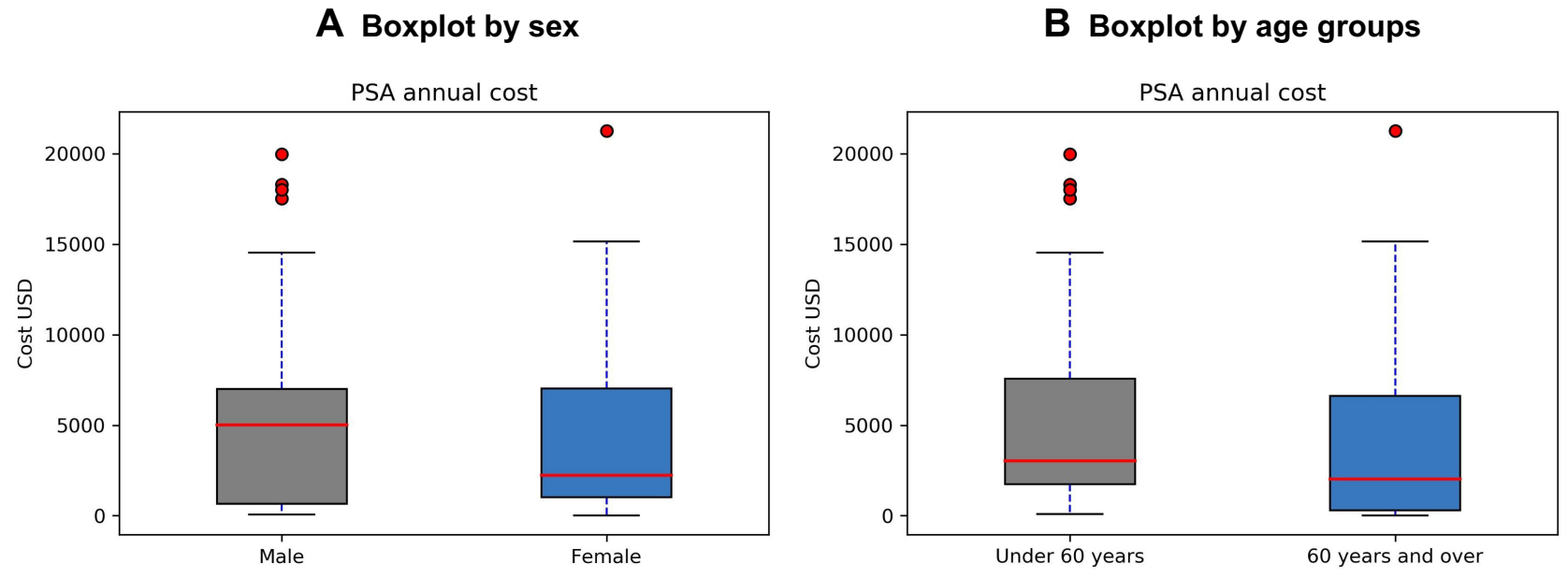

Figure 2 Cost per patient with PsA by sex and age groups and its statistical differences. (A) Boxplot by sex. (B) Boxplot by age groups.

Notes: Prepared by the authors from their data base. (A) No statistical differences in costs by sex. Mann-Whitney: $U=735, P=0.13$. (B) Statistical differences in costs by age groups. Mann-Whitney: $U=649, P=0.03$.

of a patient with PsA could vary between USD 1450-10,997, with hospitalization included. ${ }^{39}$

The cost of medicines was the item with the largest share in the total direct medical cost (97\%). In MSK, it is observed that a large proportion of the total cost is occupied by the category of medications; Mora-Claudia et $\mathrm{al}^{40}$ showed that this proportion was around $86 \%$, lower than that found in our analyzes. McHugh et al, ${ }^{41}$ for their part, stated that this item represented only $59 \%$. This last study included hospitalization, which could indicate the variation in the proportion vs our findings.

The cost of the treatment with biological therapy cost up to 7.9 times more than one with conventional therapy per patient. This difference in costs is greater than that presented by Burgos-Pol et al, ${ }^{39}$ where it shows an average increase in cost between 3 and 5 times when biological therapies are used. Likewise, Montoya et $\mathrm{al}^{42}$ suggest that this increase occurs in a range between 6.4 and 8.3 times

Table 6 Multivariate Regression Analysis of Direct Medical Costs

\begin{tabular}{|l|l|l|l|}
\hline Characteristics & Cost Ratio & $\mathbf{9 5 \%} \mathbf{C l}$ & p-value \\
\hline (Intercept) & 1269 & 920,1797 & $<0.001$ \\
\hline $\begin{array}{c}\text { Sex } \\
\text { Male (ref: female) }\end{array}$ & 0.66 & $0.46,0.97$ & 0.024 \\
\hline $\begin{array}{c}\text { Age } \\
\geq 60 \text { years (ref:<60) }\end{array}$ & 0.75 & $0.53,1.08$ & 0.11 \\
\hline Use of bDMARDs & 9.00 & $6.22,13.0$ & $<0.001$ \\
\hline
\end{tabular}

Abbreviation: $\mathrm{Cl}$, confidence interval. in the treatment of RA with biologics. Regarding consultations, in our study, the proportion of patients with rheumatological consultations was $98.8 \%$ and with dermatological consultations, it was $78.3 \%$, showing better results compared to that of Zhu et $\mathrm{al}^{43}$ with $27.1 \%$ for rheumatology consultations and $4.3 \%$ with dermatology consultations.

In PsA disease activity has been studied how a treat-totarget approach significantly improves health outcomes for newly diagnosed patients, without serious adverse events reported. ${ }^{5}$ However, tight control strategies applied in PsA are scarce in middle-income countries. On the other hand, tight control strategies have been applied for RA in Colombia, showing better health outcomes. ${ }^{44}$

This study has limitations. The first is related to the level of severity of the PsA. The disease activity of many patients was not recorded in its clinical records. For this reason, it was not possible to discriminate costs due to the severity level of the disease. The second is the direct medical costs we reported did not include hospitalization costs. In other studies, women with RA or PsA had higher direct medical costs than men because of hospitalizations and non-drug treatments, whereas drug costs were higher in men. ${ }^{45}$ We displayed major costs in men, probably because only outpatients were included in the analysis. Also, we found higher costs in younger male patients. This could be explained by the fact that maybe there is bias in the health system to treat males more aggressively and keep them working than there is for females. Therefore, analyzed patients were treated in a rheumatological center. Our results show that PsA 
patients were treated mainly by rheumatologists. Then, patients attended in a rheumatological care center are more severely ill and receive more intense therapy than the average patient of the same diagnosis treated in other type of centers, or specialists. ${ }^{46}$

On the other hand, direct medical costs were calculated from third payer perspective. Other analyses performed in PsA have displayed the economic burden from a societal perspective, including out-of-pocket health expenditures and indirect costs. ${ }^{45-47}$ Subsequently, our investigation only shows a partial economic evaluation of costs associated with PsA and represents an underestimation of the total economic burden related with this disease. Further studies should be carried out to describe the total costs owing to PsA including productivity losses due to reduced employment. ${ }^{47}$ Finally, further research is also needed to capture more accurately the relationship between disease severity and direct health care costs in middle-income settings.

The main strength of this study is that it fills an investigative gap in the generation of costs analysis of rheumatic diseases. It then becomes an important input for future cost-effectiveness analyzes of potential therapies that try to improve the health of patients with PsA.

\section{Conclusions}

Psoriatic Arthritis is a chronic pathology, treated and analyzed mainly from two medical specialties, due to joint and skin conditions, which lead to a combination of medications for the treatment of each area. This study hopes to have provided updated knowledge on the behavior in frequency and direct costs, from the provision of a rheumatic care center service, to support epidemiologic or pharmacovigilance models.

\section{Statements of Ethical Approval}

This study was approved by the Research Committee of Biomab Health Care Center in February 2019. All patients had previously signed informed consent for data use. This study did not represent risks for the patients according to the Resolution 8430 of 1993 of the Ministry of Health of Colombia. All data that could identify a patient were anonymized.

\section{Acknowledgments}

We thank Biomab Health Care Center for the administrative data provided for this study.

\section{Author Contributions}

All authors made a significant contribution to the work reported, whether that is in the conception, study design, execution, acquisition of data, analysis and interpretation, or in all these areas; took part in drafting, revising or critically reviewing the article; gave final approval of the version to be published; have agreed on the journal to which the article has been submitted; and agree to be accountable for all aspects of the work.

\section{Funding}

This research did not receive any specific grant from funding agencies in the public, commercial, or not-forprofit sectors.

\section{Disclosure}

Dr Pedro Santos-Moreno reports grants, personal fees, and non-financial support from Pfizer, Janssen, Biopas - UCB, and Abbvie, and personal fees and non-financial support from Roche, Bristol, Lilly, and Sanofi, outside the submitted work. The authors report no other potential conflicts of interest for this work.

\section{References}

1. ADAPTE Collaboration. The ADAPTE process: resource toolkit for guideline adaptation (version 2.0). Guidelines International Network, 2009.

2. Elmamoun M, Eraso M, Anderson M, et al. International league of associations for rheumatology recommendations for the management of psoriatic arthritis in resource-poor settings. Clin Rheumatol. 2020;39(6):1839-1850. doi:10.1007/s10067-020-04934-7

3. Gladman DD, Antoni C, Mease P, Clegg DO, Nash O. Psoriatic arthritis: epidemiology, clinical features, course, and outcome. Ann Rheum Dis. 2005;64(suppl 2):ii14-ii17.

4. Sokoll KB, Helliwell PS. Comparison of disability and quality of life in rheumatoid and psoriatic arthritis. J Rheumatol. 2001;28(8):1842-1846.

5. Coates LC, Moverley AR, McParland L, et al. Effect of tight control of inflammation in early psoriatic arthritis (TICOPA): a UK multicentre, open-label, randomised controlled trial. Lancet. 2015;386 (10012):2489-2498. doi:10.1016/S0140-6736(15)00347-5

6. Ritchlin CT, Colbert RA, Gladman DD. Psoriatic arthritis. $N$ Engl J Med. 2017;376(10):957-970. doi:10.1056/NEJMra1505557

7. Kavanaugh A, Helliwell P, Ritchlin CT. Psoriatic arthritis and burden of disease: patient perspectives from the population-based multinational assessment of psoriasis and psoriatic arthritis (MAPP) survey. Rheumatol Ther. 2016;3(1):91-102. doi:10.1007/s40744-016-0029-z

8. González S, Queiro R, Ballina J. Actualización en la patogenia de la artritis psoriásica [Update in the pathogenesis of psoriatic arthritis]. Reumatol Clin. 2012;8(SUPPL.1):1-6. Spanish. doi:10.1016/j.reuma.2011.12.003

9. Fernández-Ávila DG, Beltrán A, González C, et al. Traducción y validación de la versión en español del cuestionario ToPAS (Toronto Psoriatic Arthritis Screening Questionnaire), para el tamizaje de pacientes con artritis psoriásica en la consulta dermatológica en Colombia [Translation and validation of the Spanish version of the ToPAS (Toronto Psoriatic Arthritis Screening) questionnaire for use on patients with psoriatic arthritis in Dermatology clinics in Colombia]. Rev Colomb Reumatol. 2017;24(2):79-83. Spanish. 
10. Dominguez-Rosado I, Moutinho V, Dematteo RP, Kingham TP, D'Angelica M, Brennan MF. Outcomes of the Memorial Sloan Kettering Cancer Center International General Surgical Oncology Fellowship. J Am Coll Surg. 2016;222(5):961-966. doi:10.1016/j. jamcollsurg.2016.01.049

11. Villani AP, Rouzaud M, Sevrain M, et al. Prevalence of undiagnosed psoriatic arthritis among psoriasis patients: systematic review and meta-analysis. J Am Acad Dermatol. 2015;73(2):242-248. doi:10.10 16/j.jaad.2015.05.001

12. Eder L, Haddad A, Rosen CF, et al. The incidence and risk factors for psoriatic arthritis in patients with psoriasis: a prospective cohort study. Arthritis Rheumatol. 2016;68(4):915-923. doi:10.1002/art.39494

13. Ogdie A, Haynes K, Troxel AB, et al. Risk of mortality in patients with psoriatic arthritis, rheumatoid arthritis and psoriasis: a longitudinal cohort study. Ann Rheum Dis. 2014;73(1):149-153. doi:10.1136/annrheumdis-2012-202424

14. Gladman DD, Farewell VT, Wong K, Husted J. Mortality studies in psoriatic arthritis: results from a single outpatient center. II. Prognostic indicators for death. Arthritis Rheum. 1998;41 (6):1103-1110. doi:10.1002/1529-0131(199806)41:6<1103::AIDART18>3.0.CO;2-N

15. Dai YX, Hsu MC, Hu HY, et al. The risk of mortality among psoriatic patients with varying severity: a nationwide population-based cohort study in Taiwan. Int J Environ Res Public Health. 2018;15(12):2622. doi:10.3390/ijerph15122622

16. Coates LC, Kavanaugh A, Mease PJ, et al. Group for research and assessment of psoriasis and psoriatic arthritis 2015 treatment recommendations for psoriatic arthritis. Arthritis Rheumatol. 2016;68:1060-1071.

doi: 10 . 1002/art.39573

17. Gossec L, Smolen JS, Gaujoux-Viala C, et al. European league against rheumatism recommendations for the management of psoriatic arthritis with pharmacological therapies. Ann Rheum Dis. 2012;71 (1):4-12. doi:10.1136/annrheumdis-2011-200350

18. Kwan-Morley J, Marchetta P, Gladman DD, et al. 2018 American College of Rheumatology/National Psoriasis Foundation guideline for the treatment of psoriatic arthritis. $J$ Psoriasis Psoriatic Arthritis. 2018;4(1). doi:10.1177/2475530318810851.

19. Arokiasamy P, Uttamacharya KP, Capistrant BD, et al. Chronic noncommunicable diseases in 6 low- and middle-income countries: findings from wave 1 of the world health organization's Study on Global Ageing and Adult Health (SAGE). Am J Epidemiol. 2017;185 (6):414-428. doi:10.1093/aje/kww125

20. López-Estebaranz JL, Zarco-Montejo P, Escalas-Taberner J, García-Rodríguez M, García-Llorente JF, García-Calvo C. Clinical management of psoriatic arthritis in Spain: the CALIPSO study. Actas Dermosifiliogr. 2010;101(7):629-636. doi:10.1016/j. ad.2010.03.006

21. Maese J, Díaz Del Campo P, Seoane-Mato D, Guerra M, Cañete JD. Eficacia de los fármacos antirreumáticos modificadores de la enfermedad sintéticos en artritis psoriásica: una revisión sistemática. Reumatol Clin. 2018;14(2):81-89. doi:10.1016/j.reuma.2016.10.005

22. Sociedad Española de Reumatología. ESPOGUÍA: Guía de Práctica Clínica para el Tratamiento de la Espondiloartritis Axial y la Artritis Psoriásica [ESPOGUÍA: Clinical Practice Guide for the Treatment of Axial Spondyloarthritis and Psoriatic Arthritis]. Madrid; 2018. Spanish.

23. Ministerio de Salud y Protección Social [Ministry of Health and Social Protection]. Comportamiento del aseguramiento [Assurance behavior]; 2018 [cited May 21, 2020]. Available from: https://www.minsalud.gov. co/proteccionsocial/Regimensubsidiado/Paginas/coberturas-delregimen-subsidiado.aspx. Accessed February 9, 2021. Spanish.

24. Guerrero R, Isabel Gallego A, Becerril-Montekio, V, Vásquez, J. Sistema de salud de Colombia [The health system of Colombia]. Salud Pública de México. 2011;53:s144-155. Spanish.
25. Instituto Nacional de Salud - Observatorio Nacional de Salud [National Institute of Health - National Health Observatory]. Acceso a servicios de salud en Colombia [Access to health services in Colombia]. Bogotá, DC: Decimo Prim Inf Tecnico; 2019. Spanish.

26. Congi L, Roussou E. Clinical application of the CASPAR criteria for psoriatic arthritis compared to other existing criteria. Clin Exp Rheumatol. 2010;28(3):304-310.

27. Instituto de Evaluación Tecnológica en SaludIETS [Institute of Technological Evaluation in Health]. Manual para la elaboración de evaluaciones económicas en salud [Manual for the preparation of economic evaluations in health]. Bogotá, Colombia: Instituto de Evaluación Tecnológica en Salud; 2014. Spanish.

28. SISPRO. Sistema Integral de Información de la Protección Social [Comprehensive Social Protection Information System]. Spanish. Available from: https://web.sispro.gov.co/WebPublico/Consultas/ ConsultarCNPMCadenaComercializacionCircu2yPA_028_2_2.aspx. Accessed April 2020.

29. Ministerio de Salud y Protección Social [Ministry of Health and Social Protection]. Acuerdo No. 256 de 2001 - Manual de Tarifas de la Entidad Promotora de Salud del Seguro Social; 2001 [Agreement No. 256 of 2001 - Rate Manual of the Social Security Health Promotion Entity; 2001]. Spanish. Available from: https:// miscuentasmedicas.com/manual-iss-2001.

30. Instituto de Evaluación Tecnológica en Salud [Institute of Technological Evaluation in Health]. Qué es el IETS; 2018 [What is the IETS; 2018]. Spanish. Available from: https://www.iets.org.co/ IETS/IETS.aspx.

31. Banco de la República de Colombia [Bank of the Republic of Colombia]. Tasa de cambio representativa del mercado - Serie histórica de periodicidad mensual [Market representative exchange rate - Historical series of monthly periodicity]. Bogotá D.C.; 2020. Spanish. Available from: https://www.banrep.gov.co/es/estadisticas/trm.

32. Nachar N. The Mann-Whitney U: a test for assessing whether two independent samples come from the same distribution. Tutor Quant Methods Psychol. 2008;4(1):13-20. doi:10.20982/tqmp.04. 1.p013

33. Dodd S, Bassi A, Bodger K, Williamson P. A comparison of multivariable regression models to analyse cost data. J Eval Clin Pract. 2006;12(1):76-86. doi:10.1111/j.1365-2753.2006.00610.x

34. Barber J, Thompson S. Multiple regression of cost data: use of generalised linear models. J Health Serv Res Policy. 2004;9 (4):197-204. doi:10.1258/1355819042250249

35. Ministerio de Salud [Ministry of Health]. Resolución No. 8430 de 1993 [Resolution No. 8430 of 1993]; 1993 [cited November 13, 2019]. Available from: https://www.minsalud.gov.co/sites/rid/Lists/ BibliotecaDigital/RIDE/DE/DIJ/RESOLUCION-8430-DE-1993. PDF. Accessed February 9, 2021. Spanish.

36. González-Vacarezza N, Bertoldi EG, Deminco A, González G, Martínez Asuaga M. Análisis Costo-Utilidad Del Uso De Adalimumab, Etanercept E Infliximab Para El Tratamiento De La Artritis Psoriásica En Uruguay [Cost-Utility Analysis of the Use of Adalimumab, Etanercept and Infliximab for the Treatment of Psoriatic Arthritis in Uruguay]. Value Health Reg Issues. 2014;5:58-64. Spanish. doi:10.1016/j.vhri.2014.09.001

37. Lopes N, Dias LLS, Azulay-Abulafia L, et al. Humanistic and economic impact of moderate to severe plaque psoriasis in Brazil. $A d v$ Ther. 2019;36(10):2849-2865. doi:10.1007/s12325-019-01049-7

38. Merola JF, Herrera V, Palmer JB. Direct healthcare costs and comorbidity burden among patients with psoriatic arthritis in the USA. Clin Rheumatol. 2018;37(10):2751-2761. doi:10.1007/s10067-018-4187-y

39. Burgos-Pol R, Martínez-Sesmero JM, Ventura-Cerdá JM, Elías I, Caloto MT, Casado M. Coste de la psoriasis y artritis psoriásica en cinco países de Europa: Una revisión sistemática [The cost of psoriasis and psoriatic arthritis in 5 European countries: a systematic review]. Actas Dermosifiliogr. 2016;107(7):577-590. Spanish. doi:10.1016/j.ad.2016.04.018 
40. Mora C, González A, Díaz J, Quintana G. Costos directos de la artritis reumatoide temprana en el primer año de atención: simulación de tres situaciones clínicas en un hospital universitario de tercer nivel en Colombia [Direct costs of early rheumatoid arthritis in the first year of care: simulation of three clinical situations in a tertiary university hospital in Colombia]. Biomedica. 2009;29 (1):43-50. Spanish. doi:10.7705/biomedica.v29i1.40

41. McHugh N, Maguire Á, Handel I, et al. Evaluation of the economic burden of psoriatic arthritis and the relationship between functional status and healthcare costs. J Rheumatol. 2019;47(5):701-707.

42. Montoya N, Gómez L, Vélez M, Rosselli D. Costos directos del tratamiento de pacientes con artritis reumatoide en Medellín, Colombia. Rev Colomb Reumatol. 2011;18(1):26-33.

43. Zhu B, Edson-Heredia E, Gatz JL, Guo J, Shuler CL. Treatment patterns and health care costs for patients with psoriatic arthritis on biologic therapy: a retrospective cohort study. Clin Ther. 2013;35 (9):1376-1385. doi:10.1016/j.clinthera.2013.07.328
44. Santos-Moreno P, Alvis-Zakzuk NJ, Villarreal-Peralta L, Carrasquilla-Sotomayor M, Paternina-Caicedo A, Alvis-Guzmán N. A comprehensive care program achieves high remission rates in rheumatoid arthritis in a middle-income setting. Experience of a Center of Excellence in Colombia. Rheumatol Int. 2018;38 (3):499-505. doi:10.1007/s00296-017-3903-2

45. Huscher D, Merkesdal S, Thiele K, Zeidler H, Schneider M, Zink A. Cost of illness in rheumatoid arthritis, ankylosing spondylitis, psoriatic arthritis and systemic lupus erythematosus in Germany. Ann Rheum Dis. 2006;65(9):1175-1183. doi:10.1136/ard.2005.046367

46. Brodszky V, Bálint P, Géher P, et al. Disease burden of psoriatic arthritis compared to rheumatoid arthritis, Hungarian experiment. Rheumatol Int. 2009;30(2):199-205. doi:10.1007/s00296-009-0936-1

47. Poole CD, Lebmeier M, Ara R, Rafia R, Currie CJ. Estimation of health care costs as a function of disease severity in people with psoriatic arthritis in the UK. Rheumatology. 2010;49(10):1949-1956. doi:10.1093/rheumatology/keq182

\section{Publish your work in this journal}

Psoriasis: Targets and Therapy is international, peer-reviewed, open access journal focusing on psoriasis, nail psoriasis, psoriatic arthritis and related conditions, identification of therapeutic targets and the optimal use of integrated treatment interventions to achieve improved outcomes and quality of life. Visit http://www.dovepress. com/testimonials.php to read real quotes from published authors. 